\title{
Is there any relationship between the exposure to mycophenolic acid and the clinical status in children with lupus?
}

\author{
C Jurado $^{1 *}$, B Bader-Meunier ${ }^{2}$, B Ranchin ${ }^{3}$, S Decramer ${ }^{4}$, M Fischbac $^{5}$, E Bérard $^{6}$, F Saint-Marcoux ${ }^{1}$ \\ From 18th Pediatric Rheumatology European Society (PReS) Congress \\ Bruges, Belgium. 14-18 September 2011
}

\section{Background}

The clinical benefit of Therapeutic Drug Monitoring (TDM) of mycophenolate mofetil (MMF) when used in children with lupus (SLE) has been scarcely studied.

\section{Aim}

(i) To model mycophenolic acid (MPA; the active moiety of MMF) pharmacokinetic profiles (PK); (ii) to explore the relationships between exposure indices to MPA and the clinical status.in paediatric inpatients with SLE receiving a maintenance immunosuppressive therapy including MMF.

\section{Methods}

We launched a non-interventional study with analysis of clinical, biological and pharmacokinetic information. Full-PK profiles of MPA were modelled using an iterative two-stage approach (1). The clinical status was defined by the SLEDAI, the SLE being considered active for a score $\geq 6$. Relationships between MPA through concentrations $\left(\mathrm{C}_{0}\right)$, AUC (Area Under Curve) or AUC/ dose values, and the disease's activity were studied using logistic regression analysis.

\section{Results}

Twenty six children (aged 10 to 17 ) with SLEDAI score from 0 to 20 (median: 4) followed-up in 5 French centres were included. High PK interpatient variability was observed: $\mathrm{AUC}_{0-12 \mathrm{~h}}=40.51 \pm 20.49 \mathrm{mg} . \mathrm{h} /$ L. Trough concentrations $\left(\mathrm{C}_{0}\right)$ were poorly correlated analysis reported: (i) no relationship between $\mathrm{C}_{0}$ and SLEDAI; (ii) patients with an $\mathrm{AUC}_{0-12 \mathrm{~h}} /$ dose $<0.058 \mathrm{~h} /$ $\mathrm{L}$ were more likely to have an active disease $(\mathrm{OR}=4.8$; 95CI: 0.9-25.0; $\mathrm{p}=0.067$ ).

\section{Conclusion}

A tendency to a relationship between the lupus activity and the global MPA exposure was observed. Further data are needed to develop PK tools that could estimate the AUC using a limited sampling strategy and to lead prospective trials testing the clinical impact of a MMF TDM based on the AUC.

\section{Author details}

${ }^{1}$ Department of Pharmacology and INSERM UMR -S850, Limoges, France. ${ }^{2}$ Departments of Pediatry of: Hôpital Necker, AP-HP, Paris, France. ${ }^{3} \mathrm{CHU}$ Lyon, France. ${ }^{4} \mathrm{CHU}$ Toulouse, France. ${ }^{5} \mathrm{CHU}$ de Strasbourg, France. ${ }^{6} \mathrm{CHU}$ de Nice, France.

Published: 14 September 2011

\section{Reference}

1. Saint-Marcoux F, et al: Pharmacol Res 2011.

doi:10.1186/1546-0096-9-S1-P248

Cite this article as: Jurado et al:: Is there any relationship between the exposure to mycophenolic acid and the clinical status in children with lupus? Pediatric Rheumatology 2011 9(Suppl 1):P248.

to the global exposure to MPA (AUC). Multivariate

1Department of Pharmacology and INSERM UMR -S850, Limoges, France

Full list of author information is available at the end of the article

(C) 2011 Jurado et al; licensee BioMed Central Ltd. This is an open access article distributed under the terms of the Creative Commons Attribution License (http://creativecommons.org/licenses/by/2.0), which permits unrestricted use, distribution, and reproduction in any medium, provided the original work is properly cited. 